\title{
D2-40/p63 defined lymph vessel invasion has additional prognostic value in highly proliferating operable node negative breast cancer patients
}

\author{
Einar Gudlaugsson ${ }^{1}$, Ivar Skaland ${ }^{1}$, Erling Undersrud ${ }^{1}$, Emiel AM Janssen ${ }^{1}$, \\ Håvard Søiland ${ }^{2}$ and Jan PA Baak ${ }^{1}$ \\ ${ }^{1}$ Department of Pathology, Stavanger University Hospital, Stavanger, Norway and ${ }^{2}$ Endocrine and Breast \\ Surgery, Stavanger University Hospital, Stavanger, Norway
}

\begin{abstract}
Phosphohistone $\mathrm{H} 3$ assessed proliferation has strong prognostic value. Lymph vessel invasion by D2-40 is also prognostic, but D2-40 + myoepithelial expression in small ducts completely filled by solid-pattern ductal carcinoma in situ can mimic lymphovascular invasion. As myoepithelial cells are also $\mathbf{p} 63$ positive, we have investigated whether lymph vessel invasion identified by combined D2-40/p63 is stronger prognostically than by D2-40 alone, and whether it has independent prognostic value to phosphohistone H3. In 240 operable $T_{1-2} N_{0} M_{0}$ node negative invasive breast cancer patients $<71$ years, phosphohistone $\mathrm{H} 3$ was determined by quantitative immunohistochemistry and lymph vessel invasion by D2-40/p63 double immunostaining. Correlation analysis between the clinico-pathologic factors and lymph vessel invasion, and univariate and multivariate prognostic survival analysis were performed. With median 117 (range: 12-192) months follow-up, 36 patients $(15 \%)$ developed and $28(12 \%)$ died of distant metastases. Ten of the 61 patients $(16 \%)$ with cancer cells surrounded by D2-40 were p63 positive and none of these 'false lymph vessel invasion' recurred. D2-40 $+I$ p63- lymph vessel invasion occurred in $51 / 239(21 \%)$ cases and correlated with grade, mitotic activity index, phosphohistone H3, ER, cytokeratin14, and HER2. D2-40+/p63- lymph vessel invasion was strongly prognostic, but far more in women $\geq 55$ than those $<55$ years $(P<0.0001$ and 0.04$)$. With multivariate analysis, phosphohistone H3 proliferation was the strongest single prognosticator. Lymph vessel invasion had additional prognostic value to phosphohistone $\mathrm{H3}$ only in women $\geq 55$. This group of patients, without/with lymph vessel invasion, had 10 -year survival rates of 83 and $\mathbf{5 0 \%}$, respectively (hazard ratio-lymph vessel invasion $=3.0, P=0.04$; hazard ratio-phosphohistone $\mathrm{H3}=6.9, P=0.002$ ). Where age was $<55$ years, only phosphohistone $\mathrm{H} 3$ had independent prognostic value. Combinations of other features had no additional value. In conclusion, $\mathrm{T}_{1-2} \mathrm{~N}_{0} \mathrm{M}_{0}$ invasive breast cancer patients $\geq 55$ years with phosphohistone $\mathrm{H3} \geq 13, \mathrm{D} 2-40+/ \mathrm{p} 63-$ defined lymph vessel invasion identifies a subgroup with a high risk of distant metastases.

Modern Pathology (2011) 24, 502-511; doi:10.1038/modpathol.2010.199; published online 11 February 2011
\end{abstract}

Keywords: breast cancer; mitotic activity index; node negative; phosphohistone $\mathrm{H} 3$; proliferation; prognosis

Breast cancer is a heterogeneous disease, encompassing a number of distinct biological entities. Traditionally, invasive breast carcinomas are classified and treated according to hormone receptor

Correspondence: Professor Dr JPA Baak, MD, PhD, FRCPath, FIAC(Hon), Department of Pathology, Stavanger University Hospital, Box 8100, 4068 Stavanger, Norway.

E-mail: jpabaak@yahoo.com

Received 17 June 2010; revised 26 August 2010; accepted 30 August 2010; published online 11 February 2011 status, stage, grade, age, and other characteristics. More recently, classification of patients according to HER2 for selection for trastuzumab treatment has become a standard procedure in many laboratories.

Lymph node-negative breast cancer has a relatively good prognosis (10-20\% mortality). Improvement of survival with adjuvant systemic chemotherapy is less substantial in lymph nodenegative patients than in lymph node-positive patients: the typical survival improvement is $35 \%$ relative, and $10 \%$ absolute. ${ }^{1}$ Discomfort, cost, and 
the sometimes serious side effects of adjuvant systemic therapy must be balanced against the relatively good prognosis and moderately favorable prognostic treatment effect in this subgroup of patients. Accurate and reliable prognostic markers could be valuable in decision making regarding whether to use adjuvant systemic therapy or not.

Previous studies have shown that proliferation assessed by either mitotic activity index or phosphohistone H3 has strong prognostic value. ${ }^{2-4}$ This is in agreement with gene expression array studies. ${ }^{5-7}$ For example, patients with a high proliferation index in general have a 3.5-5 times higher risk of developing and dying from distant metastases than those with a low proliferation. ${ }^{2}$ In spite of their prognostic superiority, neither mitotic activity index nor phosphohistone H3 obtain an optimal accuracy and only $30-40 \%$ of patients with high proliferation die from their disease. It is therefore important to evaluate whether other potentially important and biologically understandable features have independent (additional) prognostic value. Vessel invasion is an attractive option, and its prognostic value has been known for many decades as an important marker for breast cancer progression. ${ }^{8,9}$ Lymphatic vessel invasion has been conventionally assessed on hematoxylin-eosin-stained sections, but this assessment tends to be subjective. Other studies have used immunohistochemistry to assess vessel invasion (for an overview, see Mohammed et $a l^{10}$ ). The monoclonal antibody D2-40 has often been used as a marker of lymphatic endothelium to identify tumor emboli in lymph vessels. ${ }^{11}$ However, D2-40 does not only stain lymph vessels but also breast myopethelial cells (Figure 1). The growth pattern of tumor cells surrounded by D2-40-positive myoepitelial cells generally enables distinction of ductal carcinoma in situ from lymphovascular invasion. However, D2-40 myoepithelial expression in small ducts completely filled by solid-pattern ductal carcinoma in situ can mimic the pattern expected for lymphovascular invasion. ${ }^{12}$ We have therefore used double staining for lymph vessels by D2-40 and p63 (which stains myoepithelial cell nuclei). D2-40 $+/$ p63 + are myoepithelial cells, whereas D2-40+/ p63- structures are lymph vessels. This enables a more reliable differentiation between ductal carcinoma in situ and lymphovascular invasion.

Most studies have found that lymph vessel invasion is an important prognostic marker. However, those studies often used a combination of node negative and positive breast cancers, and patients from all ages (see Table 1). Inevitably, these patients are heterogeneous both in behavior and treatment received. Therefore, the prognostic value in an important group, ie node negative operable patients at a younger age, is as yet uncertain. Therefore, we have studied lymph-node negative invasive breast cancer patients under 71 years of age only, as breast cancers in elderly patients tend to behave somewhat differently and the treatment may also be more varied. We have also investigated whether phosphohistone H3 and D2-40/p63 defined lymph vessel invasion have independent prognostic value in these patients.

\section{Materials and methods}

This study was part of a larger breast cancer study approved by the Regional Ethics Committee, the Norwegian Social Science Data Service, and the Norwegian Data Inspectorate. Paraffin-embedded material from 684 consecutive invasive breast cancer patients $<71$ years old with operable breast cancer treated between 1990 and 1997 was provided by the Department of Pathology at the Stavanger University Hospital (Stavanger, Norway). Of these patients, 384 were node negative. The following patients were excluded: patients who received adjuvant treatment $(n=90)$, patients with carcinoma in situ only or extensive carcinoma in situ with a

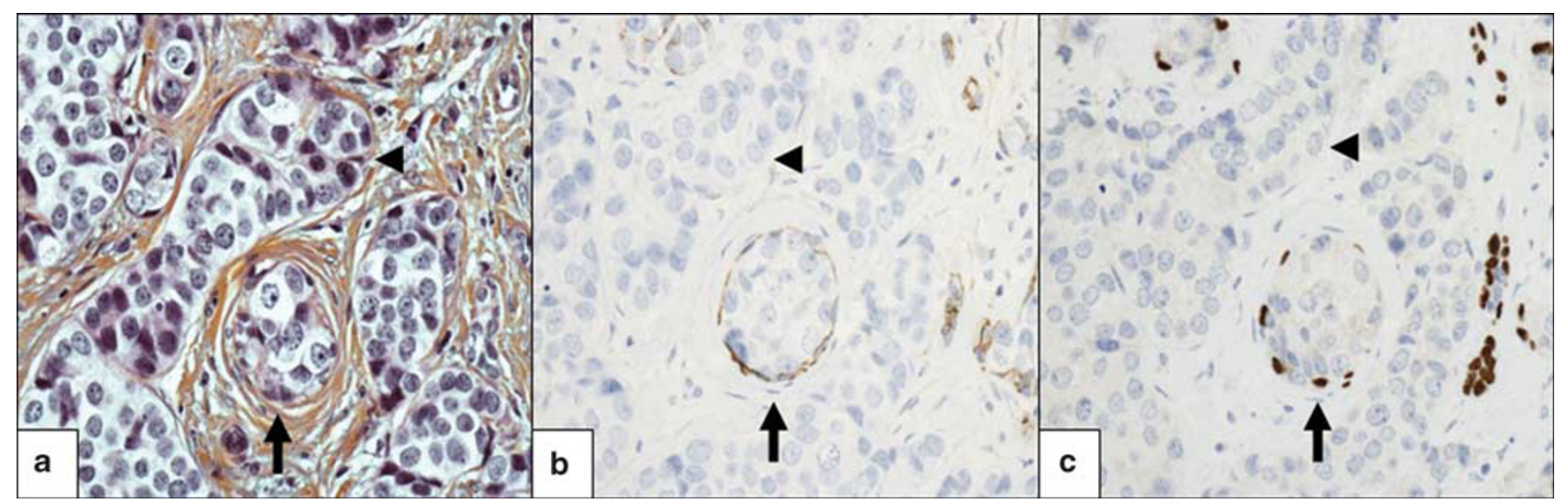

Figure 1 Overview of the histological and separate immunohistochemical stainings for D2-40 and p63 on consecutive slides. A ductal carcinoma in situ (DCIS; arrow) surrounded by invasive ductal carcinoma (arrowhead). (a) Immunohistochemical staining depicting corresponding duct with D2-40 (b) and nuclear expression for p63 (c). Note cytoplasmic expression for D2-40 in myoepithelial cells. 
Table 1 Summary of different lymph vessel invasion studies in breast cancer

\begin{tabular}{|c|c|c|c|c|c|c|c|c|c|c|c|c|c|}
\hline \# & First author & Year & $\#$ & $\begin{array}{l}\text { \# Node } \\
\text { neg }\end{array}$ & $\begin{array}{l}\text { \# Node } \\
\text { pos }\end{array}$ & $\begin{array}{l}\text { Nodal mix } \\
\text { in survival } \\
\text { analysis }\end{array}$ & $\begin{array}{l}\text { Post- } \\
\text { operative } \\
\text { systemic } \\
\text { adjuvant } \\
\text { treatment }\end{array}$ & $\begin{array}{l}\text { End point used for } \\
\text { recurrence }\end{array}$ & Recurrence & $D O D$ & $\begin{array}{l}\text { Follow-up } \\
\text { (months) }\end{array}$ & Method used & Where \\
\hline 1 & El-Gohary ${ }^{13}$ & 2008 & 48 & 24 & 24 & Yes & $\begin{array}{l}\text { Not } \\
\text { mentioned }\end{array}$ & $\begin{array}{l}\text { Any: local, } \\
\text { regional, and } \\
\text { distant }\end{array}$ & $19 \%$ & $12 \%$ & $\begin{array}{l}\text { 7-60 months; } \\
\text { mean } 33.4 \text { months }\end{array}$ & $\begin{array}{l}\text { D2-40 } \\
\text { CD31 lymph } \\
\text { vessel invasion if } \\
\text { at least one tumor } \\
\text { cell cluster clearly } \\
\text { visible in vascular } \\
\text { space }\end{array}$ & $\begin{array}{l}\text { Intratumoral and } \\
\text { peritumoral hot } \\
\text { spots }\end{array}$ \\
\hline 2 & Tezuka $^{14}$ & 2008 & 131 & 64 & 67 & Yes & Yes & Any & $41 \%$ & $18 \%$ & $\begin{array}{l}\text { 34-94 months; } \\
\text { mean } 69 \text { months }\end{array}$ & $\begin{array}{l}\text { D2-40 } \\
\text { CD34 } \\
\text { Flt-4 } \\
\text { VEGF-C; } \\
\text { Periphery and } \\
\text { fibrotic focus }\end{array}$ & $\begin{array}{l}\text { 1. Lymph vessel } \\
\text { invasion in } \\
\text { periphery } \\
\text { 2. Intratumoral } \\
\text { sinusoidal } \\
\text { structures in } \\
\text { fibrotic focus }\end{array}$ \\
\hline 3 & Ito $^{15}$ & 2007 & 69 & 44 & 25 & Yes & $\begin{array}{l}\text { Not } \\
\text { mentioned }\end{array}$ & $\begin{array}{l}\text { Unclear: Disease } \\
\text { free survival not } \\
\text { defined }\end{array}$ & $27 \%$ & Not given & Mean 47 months & $\begin{array}{l}\text { D2-40 } \\
\text { Podoplanin } 4 \text { sets } \\
\text { of } 1 \mathrm{~mm}^{2} \text {; Average } \\
\text { of these four } \\
\text { values }\end{array}$ & $\begin{array}{l}\text { 1. Outside tumor } \\
\text { 2. Inside tumor; } \\
\text { central and } \\
\text { peripheral }\end{array}$ \\
\hline 4 & Mohammed $^{10}$ & 2007 & 177 & 125 & 52 & $\begin{array}{l}\text { Any } \\
\text { recurrence }\end{array}$ & $\begin{array}{l}\text { Not } \\
\text { mentioned }\end{array}$ & $\begin{array}{l}\text { Any: locoregional } \\
\text { and distant }\end{array}$ & $23 \%$ & $9 \%$ & $\begin{array}{l}2-184, \text { mean } \\
8 \text { years }\end{array}$ & $\begin{array}{l}\text { D2-40 } \\
\text { Podoplanin } \\
\text { CD34 } \\
\text { CD31 }\end{array}$ & $\begin{array}{l}\text { 1. Outside tumor } \\
\text { 2. Inside tumor; } \\
\text { central and } \\
\text { peripheral }\end{array}$ \\
\hline 5 & $\begin{array}{l}\text { Arnaout- } \\
\text { Alkarain }^{11}\end{array}$ & 2007 & 303 & 303 & 0 & No & Yes & Any & $25 \%, 14 \%$ Distant & $16 \%$ & Median 7.6 years & $\begin{array}{l}\text { D2-40 } \\
\text { CD31 }\end{array}$ & Not mentioned \\
\hline 6 & Schoppmann $^{16}$ & 2004 & 374 & 212 & 162 & Yes & Yes & Any progression & Not mentioned & & $\begin{array}{l}\text { 8-510, Mean } 268 \\
\text { months }\end{array}$ & Podoplanin & Hot spots \\
\hline 7 & Current study & 2009 & 237 & 237 & 0 & No & No & Distant metastases & $15 \%$ & $12 \%$ & $\begin{array}{l}\text { Median } 117 \\
(12-192) \text { months }\end{array}$ & $\begin{array}{l}\text { D2-40 } \\
\text { p63 }\end{array}$ & $\begin{array}{l}\text { 1. In periphery } \\
\text { and around tumor } \\
\text { 2. In tumor center }\end{array}$ \\
\hline
\end{tabular}


Table 1 Continued

\# First author

Year \% Cases with

$\begin{array}{cl}\begin{array}{c}\text { lymph vessel } \\ \text { invasion }\end{array} & \begin{array}{l}\text { Is lymph vessel } \\ \text { invasion }\end{array}\end{array}$

invasion

invasion

significant? P-value

1 El-Gohary

2008

2008

2007

2007

2007

Arnaout

Alkarain

6 Schoppmann

2004

2010

$7 \quad$ Current study
50

Yes, 0.003

Yes, $<0.001$

23

27

28

21
Yes, $<0.001$

Yes, $<0.001$

Yes, 0.009

Yes, distant

recurrence only,

0.009

Yes, 0.0001

Yes, $<0.0001$ for

pas. $\geq 55$ years
1. Any recurrence studied

2. Unclear if lymph vessel invasion is also prognostic for distant metastases

3. Small numbers; only six patients had distant metastases

4. Short follow-up

5. Prognostic value analyzed in mixtures of node negative and positive patients with mixtures

of treatments

6. No exclusion of myoepithelial cells

1. Unclear if lymph vessel invasion is also prognostic for distant metastases

2. Many recurrences

3. Prognostic value analyzed in mixtures of node negative and positive patients with mixtures of treatments

4. No exclusion of myoepithelial cells

1. Unclear if lymph vessel invasion is also prognostic for distant metastases

2. Prognostic value analyzed in mixtures of node negative and positive patients with mixtures of treatments

\section{All stages studied}

2. Many regional recurrences $(41 / 177=23 \%)$

3. Unclear if lymph vessel invasion is significant in node negative patients

Localization of lymph vessel invasion method in tumor not defined

1. Any recurrence studied

2. Determination method unclear, only podoplanin used

3. Unclear if lymph vessel invasion is also prognostic in node negative patients only

1. Distant metastases free recurrence and overall survival studied

2. Prognostic value analyzed in node negative patients only 
small micro-invasive component $<1 \mathrm{~mm}$ that was ineligible for mitotic activity index evaluation $(n=18)$, patients with recurrence within 6 months of follow-up $(n=3),<6$-month follow-up $(n=5)$, Paget's disease $(n=1)$, bilateral breast cancer $(n=4)$, or previous other malignancies $(n=2)$. Paraffin material was not available for 21 patients, leaving 240 patients for analysis. There was no difference in age or tumor size in the 240 patients when compared with the original 384 patients. All patients were treated with either modified radical mastectomy ( $n=131)$ or breast-conserving therapy $(n=109)$, but all with adequate lymph node dissection (at least 10, median 13 nodes were examined). Locoregional radiotherapy was administered to patients who underwent breast-conserving therapy or had medially localized tumors.

\section{Pathology}

The post-surgical size of the tumor was measured in fresh specimens. Tumors were cut into $0.5 \mathrm{~cm}$ slices, fixed in $4 \%$ buffered formaldehyde, and embedded in paraffin. Paraffin sections were cut into highly standardized $4-\mu \mathrm{m}$ sections for hematoxylin-eosin and immunostaining. Histological type was assessed according to World Health Organization criteria. ${ }^{17}$ Grade (grade $1=3,4$, or 5 ; grade $2=6$ or 7 ; grade $3=8$ or 9 ) was assessed according to the Nottingham modification, ${ }^{18,19}$ calculated as the sum of tubule formation $(>75 \%=1,10-75 \%=2$, and $<10 \%=3)$, nuclear atypia (mild $=1$, moderate $=2$, and marked $=3$ ), and mitotic activity index class (0$5=1,6-10=2$, and $>10=3$ ). The mitotic activity index was assessed as described elsewhere. ${ }^{20}$ Briefly, all unambiguous mitoses were counted in 10 consecutive neighboring fields of vision in the most cell-dense area $\left(1.59 \mathrm{~mm}^{2}\right.$ at specimen level), usually in the peripheral growing zone. The mitotic activity index is insensitive to variations in tissue processing. ${ }^{21-23}$ All hematoxylin and eosin-stained sections from the tumors (median 4, range: 3-6) were reviewed and two sections were chosen for immunohistochemical analysis on the basis of: highest percentage of tumor, impression of possible lymphovascular invasion, and least tissue processing artefacts.

\section{Immunohistochemistry}

Antigen retrieval and antibody dilution were optimized prior to the study onset, similar to our previous study. ${ }^{24}$ To ensure uniform handling of samples, all sections were processed simultaneously. Paraffin sections adjacent to the hematoxylin and eosin-stained sections used for assessment of mitotic activity index and histology were mounted onto Superfrost Plus slides (Menzel, Braunschweig, Germany) and dried overnight at $37^{\circ} \mathrm{C}$ followed by $1 \mathrm{~h}$ at $60^{\circ} \mathrm{C}$ Sections were deparaffinized in xylene and rehydrated in decreasing concentrations of alcohol. Antigen was retrieved with a highly stabilized retrieval system (ImmunoPrep, Instrumec, Oslo, Norway) using $10 \mathrm{mM}$ TRIS/ $1 \mathrm{mM}$ EDTA ( $\mathrm{pH}$ 9.0) as the retrieval buffer. Sections were heated for $3 \mathrm{~min}$ at $110^{\circ} \mathrm{C}$ followed by $10 \mathrm{~min}$ at $95^{\circ} \mathrm{C}$ and cooled to $20^{\circ} \mathrm{C}$. Rabbit polyclonal antiphosphohistone H3 (ser 10) (Upstate \#06-570; Lake Placid, NY, USA) was used at a dilution of 1:1500. ER (clone SP1, Neomarkers/LabVision, Fremont, CA, USA) was used at a dilution 1/400. PR (Clone SP2, Neomarkers/LabVision) was used at a dilution of $1 / 1000$.

Anti-phosphohistone H3 was incubated for $60 \mathrm{~min}$ at $22^{\circ} \mathrm{C}$. All other antibodies were incubated for $30 \mathrm{~min}$ at $22^{\circ} \mathrm{C}$. For HER2 assessment, the HercepTest kit (Dako, Glostrup, Denmark) was used according to the manufacturer's FDA-approved procedures. HercepTest $2+$ and $3+$ cases were retested with the PathVysion (Vysis, Downers Grove, IL, USA) assay following the manufacturer's FDAapproved recommended protocols. Only HER2 amplified cases were regarded as positive.

The sections were incubated with a primary antibody cocktail of p63 (Dako, clone 4A4) and D240 (Dako, clone D2-40). The primary antibodies were diluted to a final dilution of 1:1200 and 1:200, respectively. Dako antibody diluent (S0809) was used. The EnVision ${ }^{\mathrm{TM}}$ Flex detection system (Dako, K8000) was used for visualization. Sections were incubated for $5 \mathrm{~min}$ with peroxydase-blocking reagent (SM801), 20 min with the EnVision ${ }^{\mathrm{TM}}$ FLEX/HRP Detection Reagent (SM802), 10 min with EnVision $^{\mathrm{TM}}$ FLEX DAB + Chromogen (DM827)/ EnVision $^{\mathrm{TM}}$ FLEX Substrate Buffer (SM803) mix and 5 min with EnVision ${ }^{\text {TM }}$ FLEX Hematoxylin (K8008). The slides were then dehydrated and mounted. All immunohistochemical stainings were performed using a Dako Autostainer Link 48 instrument and EnVision $^{\mathrm{TM}}$ FLEX Wash Buffer (DM831).

\section{Quantification of Phosphohistone H3-Positive Nuclei}

The phosphohistone H3 index was assessed as follows: using the same counting protocol as for the mitotic activity index, two independent pathologists counted the number of phosphohistone H3positive objects (nuclei and mitoses) in 10 adjacent fields of vision, with a $\times 40$ objective, as described above, in the same invasive epithelial portions of the most phosphohistone H3-positive areas. Nuclei with fine granular phosphohistone $\mathrm{H} 3$ staining were not counted, as these cells are not in the G2 phase. ${ }^{25}$ Phosphohistone H3-rich areas are usually localized in the periphery (ie, growing zone) of the cancers. If the counts of the two observers differed by more than three figures, the count was repeated with a multi-head microscope and a consensus score was obtained. In addition to performing subjective counts, phosphohistone H3 expression was evaluated using the fully automated VIS analysis system 
(Visiopharm, Hørsholm, Denmark), and using the same image processing principles as described before. ${ }^{24}$ Reproducibility of the phosphohistone H3 measurements between subjective counts by two observers, and between subjective and digital image analysis results was high $(R=0.94-0.98)$. Not surprisingly, the reproducibility of the phosphohistone H3 counts by the automated digital image analysis on different days by different observers was close to perfect $(R=0.99) .^{3}$

\section{Evaluation of D2-40/p63 IHC Lymph Vessel Invasion}

All sections were carefully and completely scanned by two of the authors (EG and EU) without knowledge of the lymph vessel invasion status based on hematoxylin and eosin slide or the original report. The presence of an intraluminal tumor cluster completely surrounded by strong cytoplasmic D240 expression by lymphatic endothelial cells without p63 nuclear staining was considered true lymph vessel invasion (D2-40+/p63-) and both were registered per case (Figure 2). The results were analyzed as lymph vessel invasion negative or positive, and the number of lymph vessel invasion + per $\mathrm{mm}^{2}$ cancer tissue was also evaluated. Intratumoral lymphatic vessels were extremely rare $(n=7)$, whereas most lymphatic vessels were located at the boarder of the invasive tumor front and surrounding stroma, as reported previously. ${ }^{12,16}$

\section{Data Analysis}

Correlations were calculated using the Spearman and $\kappa$ tests. For survival analysis, the main end points were distant metastases recurrence,

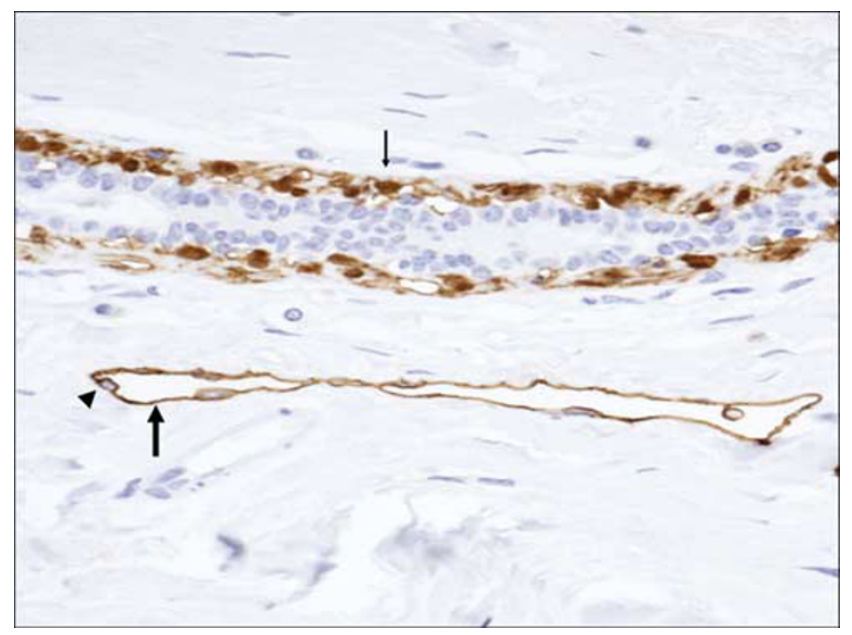

Figure 2 Double immunostaining. D2-40 reacts with lymphatic epithelium (broad arrow) and myoepithelium of segmental duct. Note p63 expression in myoepithelial cells nuclei (thin arrow) and absence of expression in a lymphatic cell nucleus (arrowhead). and overall distant metastases-related survival (a previous study on node negative patients showed that lymph vessel invasion was only prognostic for distant metastases ${ }^{11}$ ). To determine the probability that patients would remain free of distant metastases, we defined recurrence as any first recurrence at a distant site. Patients were censored from the date of the last follow-up visit for death from causes other than breast cancer, local or regional recurrences, or the development of a second, primary cancer, including contralateral breast cancer. If a patient's status during follow-up indicated a confirmed metastasis without a recurrence date, the follow-up visit date was used. Age, time to first recurrence, and survival time were calculated relative to the primary diagnosis date. For the mitotic activity index, three sets of previously established prognostic thresholds $(<6,6-10$, $\geq 11,{ }^{26}<10$ vs $\geq 10$; and $<3,3-9$, and $\left.\geq 10\right)^{27}$ were examined. There was a continuous spectrum of phosphohistone H3 values from very few, to many, positive nuclei. For survival analysis, these continuous data were divided into different subgroups, using a threshold value. We used receiver operating curves to identify the objectively optimal threshold. Kaplan-Meier survival curves were constructed, and between-group differences were tested using the log-rank test. The relative importance of potential prognostic variables was tested using Coxproportional hazard analysis and expressed as a hazard ratio with a $95 \%$ confidence interval.

The results are presented in accordance with reporting recommendations for tumor marker prognostic studies criteria. ${ }^{28}$

\section{Results}

With median 117 (range: 12-192) months follow-up, distant metastases occurred in 36 patients $(15 \%)$, with $28(12 \%)$ dying of metastases. Lymph vessel invasion was seen in $51 / 240=21 \%$ of the cases. D240 staining showed that very few lymph vessels were present within the tumor mass and most of the lymphatic channels were peritumoral. The D2-40 staining pattern in lymphatic endothelium was strong and cytoplasmic. In some cases, the tumor emboli either nearly filled or completely filled the lymphatic space mimicking solid-type ductal carcinoma in situ, but lack of p63 nuclear expression proved these emboli to be true lymph vessel invasion (Figure 3). Ten of 61 cancers $(16 \%)$ with D2-40 'lymph vessel invasion' were p63 positive and none of these recurred. We, therefore, only considered D2-40 + /p63 - as lymph vessel invasion. The presence of $\mathrm{D} 2-40+/ \mathrm{p} 63-$ lymph vessel invasion correlated with grade, mitotic activity index, phosphohistone H3, ER, CK14, HER2 (correlation with age was insignificant, $P=0.08$ ). Table 2 shows the results of univariate survival analysis. Lymph vessel invasion was prognostic (Figure 4), but much 


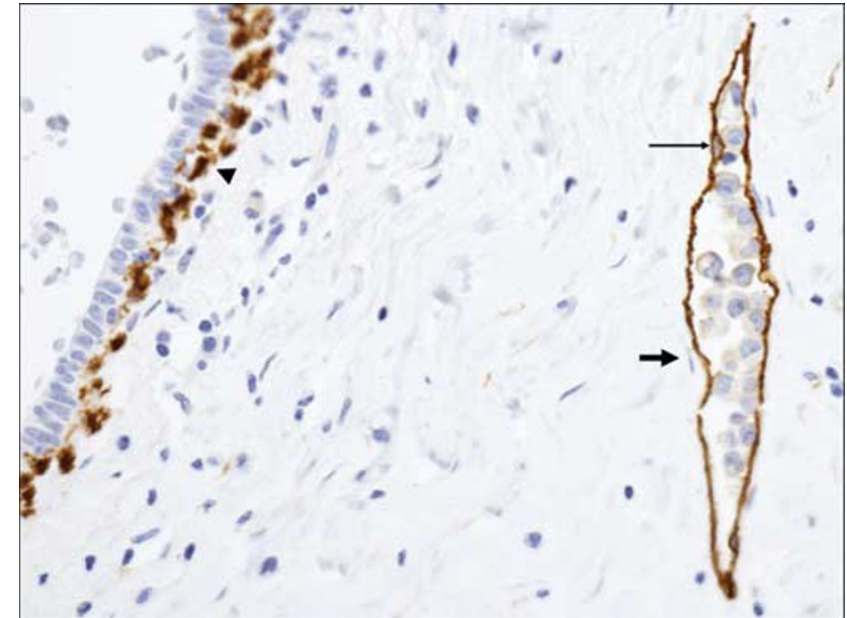

Figure 3 Double immunostaining. Cluster of tumor cells within a D2-40-stained lymph vessel (broad arrow). Benign duct on left with nuclear p63 expression (arrowhead) and absence of expression in lymphatic cells nuclei (thin arrow).

stronger in older women of $\geq 55$ years $(P<0.0001$, hazard ratio $=5.9)$ than $<55$ years $(P=0.04$, hazard ratio $=2.7$ ). With multivariate analysis (Tables 3 and 4), phosphohistone $\mathrm{H} 3$ was the strongest single feature (hazard ratio $=9.6, P<0.001$ ). Lymph vessel invasion had additional prognostic value (hazard ratio $=3.0, P=0.04$ ) to phosphohistone H3 (hazard ratio $=6.9, P=0.002$ ) (Figure 5). However, where age was $<55$ years, only phosphohistone H3 had independent prognostic value $(P=0.006)$, but not lymph vessel invasion $(P=0.22)$ nor any of the other features studied. In women $\geq 55$ years with phosphohistone $\mathrm{H} 3 \geq 13$, lymph vessel invasion absent or present gave 83 and $50 \%$ 10-year survival rates $(P=0.04)$, respectively, but if phosphohistone $\mathrm{H} 3<13$, lymph vessel invasion was not significant $(P=0.26)$. Other combinations of features had no additional value to phosphohistone H3.

\section{Discussion}

Previous studies have shown that proliferation assessed by either mitotic activity index or phosphohistone H3 has strong prognostic value. Lymph vessel invasion is promising, but the results are often conflicting. For example, in hematoxylin and eosin sections, the assessment is too subjective. D240 is much better, but next to lymph vessels it also stains myoepithelial cells, which can lower the prognostic accuracy. Double staining by D2-40 and p63 can distinguish lymph vessels and myoepithelial cells. In the present study of $\mathrm{T}_{1-2} \mathrm{~N}_{0} \mathrm{M}_{0}$ node negative breast cancer patients, we found that $16 \%$ of all cancers with D2-40-only defined lymph vessel invasion, are positive for p63. Those structures thus reflect myoepithelial expression in small ducts completely filled by solid-pattern ductal carcinoma in situ and mimick lymphovascular invasion. None
Table 2 Results of univariate survival analysis of the features studied

\begin{tabular}{|c|c|c|c|c|c|}
\hline & \multicolumn{2}{|c|}{$\begin{array}{l}\text { No lymphovascular } \\
\text { invasion }(\mathrm{n}=189)\end{array}$} & \multicolumn{2}{|c|}{$\begin{array}{l}\text { Lymphovascular } \\
\text { invasion }(\mathrm{n}=51)\end{array}$} & \multirow[b]{2}{*}{$\mathrm{P}$} \\
\hline & $\mathrm{n}$ & $\%$ & $\mathrm{n}$ & $\%$ & \\
\hline \multicolumn{6}{|l|}{ Age (years) } \\
\hline$<55$ & 78 & 74 & 28 & 26 & 0.08 \\
\hline$\geq 55$ & 111 & 83 & 23 & 17 & \\
\hline \multicolumn{6}{|c|}{ Tumor diameter grade } \\
\hline$\leq 2 \mathrm{~cm}$ & 164 & 80 & 40 & 20 & 0.1 \\
\hline$>2 \mathrm{~cm}$ & 25 & 69 & 11 & 31 & \\
\hline 1 & 75 & 93 & 6 & 7 & 0.001 \\
\hline 2 & 79 & 73 & 29 & 27 & \\
\hline 3 & 35 & 69 & 16 & 31 & \\
\hline \multicolumn{6}{|l|}{ РРНЗ } \\
\hline$<13$ & 135 & 87 & 21 & 13 & $<0.001$ \\
\hline$\geq 13$ & 54 & 64 & 30 & 36 & \\
\hline \multicolumn{6}{|l|}{$M A I$} \\
\hline $0-5$ & 128 & 87 & 19 & 13 & $<0.001$ \\
\hline $6-9$ & 21 & 72 & 8 & 28 & \\
\hline$\geq 10$ & 40 & 63 & 24 & 37 & \\
\hline \multicolumn{6}{|l|}{$E R$} \\
\hline Positive & 160 & 80 & 39 & 20 & 0.02 \\
\hline Negative & 29 & 71 & 12 & 29 & \\
\hline \multicolumn{6}{|l|}{$P R$} \\
\hline Positive & 133 & 81 & 32 & 19 & 0.7 \\
\hline Negative & 56 & 75 & 19 & 25 & \\
\hline \multicolumn{6}{|l|}{$T N P$} \\
\hline Not TNP & 169 & 80 & 43 & 20 & 0.3 \\
\hline TNP & 20 & 71 & 8 & 29 & \\
\hline \multicolumn{6}{|l|}{ CK5/6 } \\
\hline Negative & 172 & 80 & 43 & 20 & 0.7 \\
\hline Positive & 17 & 68 & 8 & 32 & \\
\hline \multicolumn{6}{|l|}{ CK14 } \\
\hline Negative & 176 & 80 & 45 & 20 & 0.04 \\
\hline Positive & 13 & 68 & 6 & 32 & \\
\hline \multicolumn{6}{|l|}{$F F$} \\
\hline Absent & 136 & 80 & 35 & 20 & 0.6 \\
\hline Present & 39 & 76 & 12 & 24 & \\
\hline \multicolumn{6}{|l|}{$B L C$} \\
\hline Not BLC & 175 & 80 & 44 & 20 & 0.2 \\
\hline BLC & 14 & 67 & 7 & 33 & \\
\hline \multicolumn{6}{|l|}{ HER2 } \\
\hline Negative & 176 & 82 & 38 & 18 & $<0.001$ \\
\hline Positive & 13 & 50 & 13 & 50 & \\
\hline
\end{tabular}

BCT, breast concerving therapy; BLC, basal-like carcinoma; CK14, cytokeratin 14; CK5/6, cytokeratin 5/6; ER, estrogen receptor; FF, fibrotic focus; HER2, human epidermal growth factor receptor 2; MAI, mitotic activity index; MRM, modified radical mastectomy; PPH3, phosphohistone H3; PR, progesterone receptor; TNP, triple negative carcinoma; P, probability of no difference.

of these patients recurred. However, lymph vessel invasion defined by combined D2-40 and p63 has strong prognostic value. Further analysis showed that this is mostly in women $\geq 55$ years 
of age, especially with highly proliferating cancers (ie, phosphohistone $\mathrm{H} 3 \geq 13$ ) where lymph vessel invasion assessed by $\mathrm{D} 2-40+/ \mathrm{p} 63-$ identifies a subgroup of $10 \%$ of all patients with a very high risk of distant metastases. In women $<55$ years, only phosphohistone H3 had independent prognostic value.

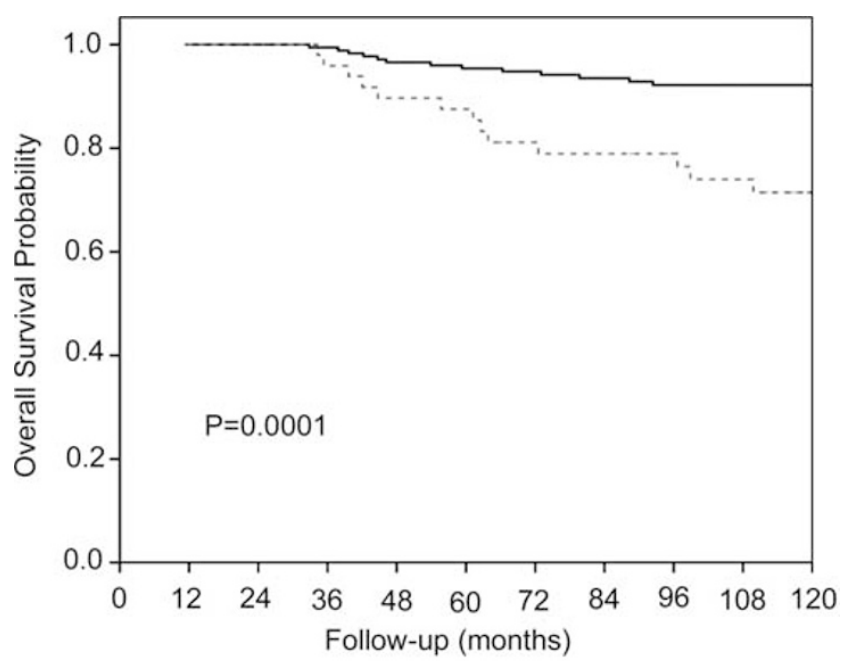

Number at risk

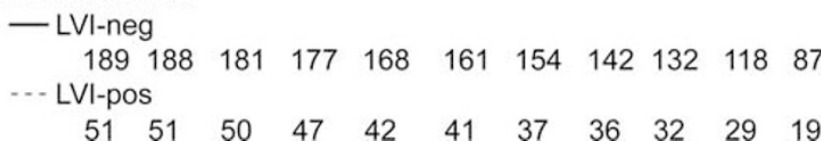

Figure 4 Survival of patients with and without D2-40+/p63lymph vessel invasion (LVI).
This is an important finding, as lymph vessel invasion has been proposed as a criterion for adjuvant chemotherapy. However, this improves the prognosis mostly in node negative breast cancer patients $<55$ years. We showed that in these patients, lymph vessel invasion has no additional prognostic value to phosphohistone H3. This makes adjuvant chemotherapy in patients with lymph vessel invasion but low proliferation, a highly questionable procedure.

One problem of the combined D2-40/p63 analysis is that it is time consuming. The question therefore is whether lymph vessel invasion is of any value at all in selecting node negative breast cancer patients for adjuvant chemotherapy, as phosphohistone $\mathrm{H} 3 \geq 13$ is already associated with a poor prognosis, and lymph vessel invasion negativity still shows a $17 \%$ risk of developing distant metastases. Gene signature studies have set the risk threshold for no-adjuvant treatment at 5-10\%. Obviously, a 17\% distant metastases risk may in general be too high to not give adjuvant chemotherapy, but this may vary from patient to patient, and from one country to the other.

We conclude that in operable $\mathrm{T}_{1-2} \mathrm{~N}_{0} \mathrm{M}_{0}$ invasive breast cancer patients, lymph vessel invasion has strong prognostic value but mostly in women $\geq 55$ years of age with phosphohistone $H 3 \geq 13$, where lymph vessel invasion assessed by $\mathrm{D} 2-40+/ \mathrm{p} 63-$ identifies a subgroup with a very high risk of distant metastases. In women $<55$ years, only phosphohistone $\mathrm{H} 3$ has independent prognostic value.

Table 3 With multivariate analysis, only phosphohistone H3 (PHH3) (with a threshold of 13) and lymph vessel invasion (LVI) had independent prognostic value

\begin{tabular}{|c|c|c|c|c|c|c|}
\hline \multirow[t]{2}{*}{ Variable combination } & \multirow[t]{2}{*}{$\beta$} & \multirow[t]{2}{*}{ Standard error } & \multirow[t]{2}{*}{ Probability of no difference } & \multirow[t]{2}{*}{ Hazard ratio } & \multicolumn{2}{|c|}{$95 \%$ CI hazard ratio } \\
\hline & & & & & Lower & Upper \\
\hline \multicolumn{7}{|l|}{ Step 1} \\
\hline РРН3 (13) & 2.3 & 0.58 & 0.000 & 9.6 & 3.1 & 29.9 \\
\hline \multicolumn{7}{|l|}{ Step 2} \\
\hline LVI & 1.1 & 0.53 & 0.04 & 2.9 & 1.6 & 8.4 \\
\hline РРН3 (13) & 1.9 & 0.61 & 0.002 & 6.9 & 2.1 & 22.7 \\
\hline
\end{tabular}

Variables not in the Equation ${ }^{\mathrm{a}, \mathrm{b}}$

\begin{tabular}{llll}
\hline & Score & $d f$ & Sig. \\
\hline Step 1 & & & \\
LVI & 4.6 & 1 & 0.03 \\
HER2 & 0.03 & 1 & 0.87 \\
ER & 0.002 & 1 & 0.96 \\
PR & 1.2 & 1 & 0.28 \\
Step 2 & & & \\
HER2 & 0.32 & 1 & 0.56 \\
ER & 0.03 & 1 & 0.86 \\
PR & 0.48 & 1 & 0.48 \\
\hline
\end{tabular}

${ }^{\mathrm{a}}$ Residual $\chi^{2}=6.939$ with $4 \mathrm{df}$ Sig. $=0.139$.

${ }^{\mathrm{b}}$ Residual $\chi^{2}=2.233$ with $3 \mathrm{df}$ Sig. $=0.525$. 
Table 4 Combined phosphohistone H3 (PPH3) and lymph vessel invasion (LVI) has strong prognostic value

\begin{tabular}{lccccc}
\hline Variable combination & $\beta$ & Standard error & Probability of no difference & Hazard ratio & 95\% CI hazard ratio \\
\cline { 3 - 5 } & & & & Lower \\
\hline PPH3 < 13, LVI neg & & & $<0.0001$ & \\
PPH3 < 13, LVI pos & 0.5 & 1.12 & 0.69 & 0.2 \\
PPH3 > 13, LVI neg & 1.8 & 0.59 & 0.002 & 1.6 & 1.9 \\
PPH3 > 13, LVI pos & 2.8 & 0.57 & $<0.0001$ & 16.9 & 19.7 \\
\hline
\end{tabular}

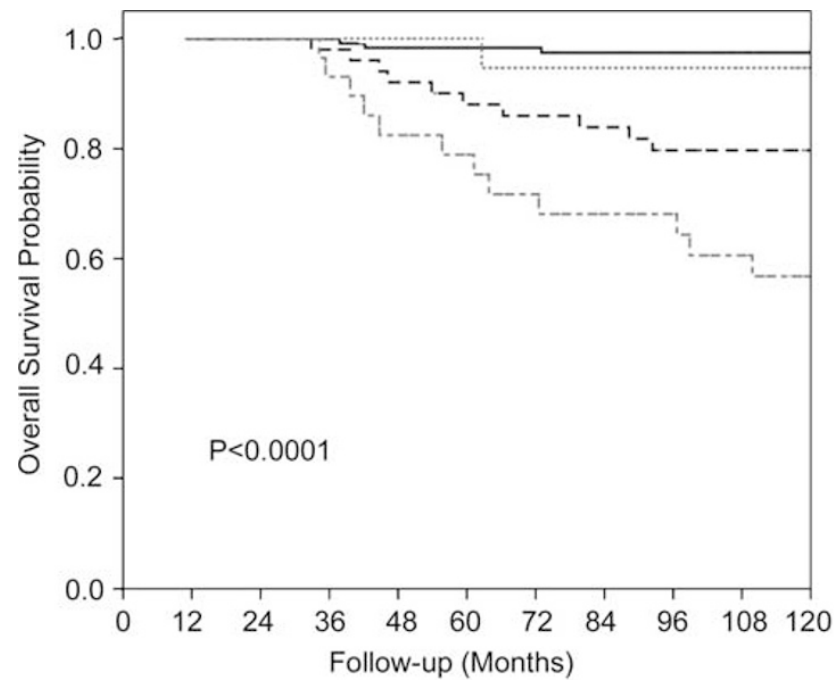

Number at risk

\begin{tabular}{|c|c|c|c|c|c|c|c|c|c|}
\hline \multicolumn{10}{|c|}{ — $\mathrm{PPH} 3<13$, LVI-neg } \\
\hline 135 & 134 & 129 & 126 & 122 & 118 & 112 & 102 & & \\
\hline \multicolumn{10}{|c|}{....PPH3< 13, LVI-pos } \\
\hline 21 & 21 & 20 & 20 & 19 & 19 & 17 & 17 & 1 & \\
\hline \multicolumn{10}{|c|}{ - -PPH3 $\geq 13$, LVI-neg } \\
\hline 54 & 54 & 52 & 51 & 46 & 43 & 42 & 40 & 3 & \\
\hline \multicolumn{10}{|c|}{-PPH3 $\geq 13$, LVI-pos } \\
\hline 30 & 30 & 30 & 27 & 23 & 22 & 20 & 19 & & \\
\hline
\end{tabular}

Figure 5 Combined phosphohistone $\mathrm{H} 3$ (PPH3) and lymph vessel invasion (LVI) has strong prognostic value.

\section{Acknowledgement}

This work was supported in part by the Stichting Bevordering Diagnostische Pathologie, Middelburg, The Netherlands.

\section{Disclosure/conflict of interest}

The authors declare no conflict of interest.

\section{References}

1 Early Breast Cancer Trialists' Collaborative Group (EBCTG). Effects of chemotherapy and hormonal therapy for early breast cancer on recurrence and 15year survival: an overview of the randomized trials. Lancet 2005;365:1687-1717.
2 Baak JP, van Diest PJ, Voorhorst FJ, et al. Prospective multicenter validation of the independent prognostic value of the mitotic activity index in lymph nodenegative breast cancer patients younger than 55 years. J Clin Oncol 2005;23:5993-6001.

3 Skaland I, Janssen EA, Gudlaugsson E, et al. Validating the prognostic value of proliferation measured by PPH3 (phosphohistone H3) in invasive lymph nodenegative breast cancer patients less than 71 years of age. Breast Cancer Res Treat 2009;114:39-45.

4 Baak JP, Gudlaugsson E, Skaland I, et al. Proliferation is the strongest prognosticator in node-negative breast cancer: significance, error sources, alternatives and comparison with molecular prognostic markers. Breast Cancer Res Treat 2009;115:241-254.

5 Sotiriou C, Wirapati P, Loi S, et al. Gene expression profiling in breast cancer: understanding the molecular basis of histologic grade to improve prognosis. J Natl Cancer Inst 2006;98:262-272.

6 Liu J, Campen A, Huang S, et al. Identification of a gene signature in cell cycle pathway for breast cancer prognosis using gene expression profiling data. BMC Med Genomics 2008;11:1-39.

7 Haibe-Kains B, Desmedt C, Sotiriou C, et al. A comparative study of survival models for breast cancer prognostication based on microarray data: does a single gen beat them all? Bioinformatics 2008;24: 2200-2208.

8 Rosen P, Groshen S, Kinne DW. Prognosis in T2N0M0 stage I breast carcinoma: a 20-year follow-up study. J Clin Oncol 1991;9:1650-1655.

9 Lauria R, Perrone F, Carlomagno C, et al. The prognostic value of lymphatic and blood vessel invasion in operable breast cancer. Cancer 1995;76:1772-1775.

10 Mohammed RA, Martin SG, Gill MS, et al. Improved methods of detection of lymphovascular invasion demonstrate that it is the predominant method of vascular invasion in breast cancer and has important clinical consequences. Am J Surg Pathol 2007;31: 1825-1833.

11 Arnaout-Alkarain A, Kahn HJ, Narod SA, et al. Significance of lymph vessel invasion identified by the endothelial lymphatic marker D2-40 in node negative breast cancer. Mod Pathol 2007;20:183-191.

12 Rabban JT, Chen YY. D2-40 expression by breast myoepithelium: potential pitfalls in distinguishing intralymphatic carcinoma from in situ carcinoma. Hum Pathol 2008;39:175-183.

13 El-Gohary YM, Metwally G, Saad RS, et al. Prognostic significance of intratumoral and peritumoral lymphatic density and blood vessel density in invasive breast carcinoma. Am J Clin Pathol 2008;129:578-586. 
14 Tezuka K, Onoda N, Takashima T, et al. Clinical significance of intra-tumoral sinusoidal structures showing lympho-endothelial immunoreactivity in breast cancer. Oncol Rep 2008;20:25-32.

15 Ito M, Moriya T, Usami S, et al. Significance of pathological evaluation for lymphatic vessel invasion in invasive breast cancer. Breast Cancer 2007;14: 381-387.

16 Schoppmann SF, Bayer G, Aumayr K, et al. Prognostic value of lymphangiogenesis and lymphovascular invasion in invasive breast cancer. Ann Surg 2004; 240:306-311.

17 Tavassoli FA, Devilee P, (eds). Pathology and Genetics: Tumours of the Breast and Female Genital Tract Organs; WHO Classification Tumours Series. IARC Press: Lyon, 2003, pp 9-112.

18 Elston CW, Ellis IO. Pathological prognostic factors in breast cancer. I. The value of histological grade in breast cancer: experience from a large study with a long-term follow-up. Histopathology 1991;19:403-410.

19 Ellis IO, Schnitt SJ, Sastre-Garu X, et al. Invasive breast carcinoma. In: Tavassoli FA, Devilee P (eds). Pathology and Genetics of the Female Genital Tract Organs. IARC Press: Lyon, 2003, pp 18-19.

20 Baak JP, van Diest PJ, Ariens AT, et al. The multicenter morphometric mammary carcinoma project (MMMCP). A nationwide prospective study on reproducibility and prognostic power of routine quantitative assessments in The Netherlands. Pathol Res Pract 1989;185:664-670.

21 van Diest PJ, Baak JP, Matze-Cok P, et al. Reproducibility of mitoses counting in 2469 breast cancer specimens: results from the Multicenter Morphometric Mammary Carcinoma Project. Hum Pathol 1992;23: 603-607.

22 Jannink I, Risberg B, van Diest PJ, et al. Heterogeneity of mitotic activity in breast cancer. Histopathology 1996;29:421-428.

23 Bergers E, Jannink I, van Diest PJ, et al. The influence of fixation delay on mitotic activity and flow cytometric cell cycle variables. Hum Pathol 1997;28: 95-100.

24 Skaland I, Janssen EA, Gudlaugsson E, et al. Phosphohistone H3 expression has much stronger prognostic value than classical prognosticators in invasive lymph node-negative breast cancer patients less than 55 years of age. Mod Pathol 2007;12:1307-1315.

25 Bossard C, Jarry A, Colombeix C, et al. Phosphohistone H3 labelling for histoprognostic grading of breast adenocarcinomas and computer-assisted determination of mitotic index. J Clin Pathol 2006;59:706-710.

26 Sloane JP, Amedoeira I, Apostolikas N, et al. Consistency achieved by 23 European pathologists from 12 countries in diagnosing breast disease and reporting prognostic features of carcinomas. European Commission Working Group on Breast Screening Pathology. Virchows Arch 1999;434:3-10.

27 Baak JP, van Diest PJ, Voorhorst FJ, et al. The prognostic value of proliferation in lymph-node-negative breast cancer patients is age dependent. Eur J Cancer 2007;43:527-535.

28 McShane LM, Altman DG, Sauerbrei W, et al. Reporting recommendations for tumor marker studies. J Clin Oncol 2005;23:9067-9072. 